\title{
Are preschoolers expected to learn difficult science constructs? A content analysis of U.S. standards
}

\author{
Ana Ocasio', Talia Waltzer², Camilla Caudy³, Heidi Kloos ${ }^{4}$
}

\begin{abstract}
In the current paper, we report on the recommendations for preschool science put forward in the educational standards of U.S. states. Our focus was specifically on whether educational standards recommend abstract science constructs-constructs that are difficult to learn. In Study 1, we focused on science constructs related to inquiry (i.e., activities geared towards the generation of scientific knowledge). And in Study 2, we focused on science constructs related to facts (i.e., established scientific knowledge). In each study, we developed a coding scheme to distinguish between concrete and abstract constructs and then determined the relative prevalence of each. Our findings show that preschoolers are indeed expected to learn abstract science constructs. At the same time, educational standards varied considerably across U.S. states. Implications for the field of early science learning are discussed.
\end{abstract}

\section{Article History}

Received: 21 August 2021

Accepted: 01 December 2021

\section{Keywords}

Early science learning

Readiness standards;

Educational policy; Abstract

reasoning; Content analysis

\section{Introduction}

With science education becoming increasingly popular in preschool classrooms (Educational Development Center, 2013; National Center for Educational Statistics [NCES], 2021), many have hailed this development as a positive move toward supporting science learning in later grades (Guo et al., 2016; Piasta et al., 2014). In the current paper, we seek to further contribute to this development by asking a simple question: What is actually meant by preschool science? Our research was motivated by perceived points of tension in the field of early science learning. In what follows, we describe these points of tension and illustrate why they might need to be resolved before preschool science education becomes commonplace.

\section{Tensions in The Field of Early Science Learning}

Research on early science learning has increased substantially over the last three decades. For example, a search for the keyword "early science learning" on Google Scholar shows a three-fold increase in scholarly work over the years from 2000 to 2013 (from 250,000 to 850,000 entries). The search term "preschool science" reveals an even more dramatic increase during that time frame (from about 8,000 to 40,000 entries). This increase in scholarly work has led to important insights in the field (for reviews, see Guo et al., 2016; Kloos et al., 2012). Yet, the amount of scholarly work has decreased visibly recently (e.g., from about 40,000 to 29,000 "preschool science" entries in the years from 2015 to 2020).

Upon surveying the literature about what might be the issue, one finding was striking: Preschool teachers often have reservations about teaching science to young children (Park et al., 2017). For example, many teachers report that they do not have enough mastery of science content (Blonder et al., 2014; Oppermann et al., 2021). In turn, they might feel underprepared when using science materials (Kloos et al., 2018). Many also report lacking the confidence to organize the preschool classroom in ways that support science activities (Gerde et al., 2018). Teachers also perceive barriers when it comes to evaluating students

\footnotetext{
${ }^{1}$ University of Cincinnati, Department of Psychology, Cincinnati, Ohio, United States, e-mail: ocasioar@mail.uc.edu, ORCID: https://orcid.org/0000-0001-6183-1092

${ }^{2}$ University of California, Santa Cruz, Psychology Department, Santa Cruz, California, United States, e-mail: twaltzer@ucsc.edu, ORCID: https://orcid.org/0000-0003-4464-0336

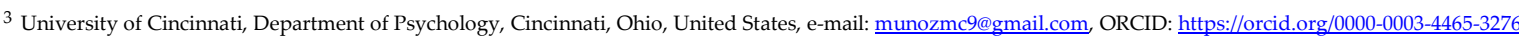

${ }^{4}$ University of Cincinnati, Department of Psychology, Cincinnati, Ohio, United States, e-mail: kloosa@ucmail.uc.edu, ORCID: https://orcid.org/0000-0003-0586-9306
} 
on science assignments, compared to other fields (Greenfield, 2015).

More generally, the question of whether early science learning has positive long-term effects is still open. On the one hand, some have argued that mere exposure is enough to give children an advantage for later learning (e.g., Kachergis et al., 2019; Kelemen et al., 2014; Saidi \& Sigauke, 2017; Shtulman et al., 2016; Worth, 1999). This argument might explain the numerous online resources designed to make science learning fun (e.g., education.com, 2012). On the other hand, science in preschool does not consistently translate into later science proficiency: Exposure to early science education might not predict improved science performance in older children (Brenneman et al., 2009; Saçkes et al., 2010; Saçkes et al., 2013).

There is also ambiguity about the amount of effort needed to bring science to young children. On the one hand, there is the appealing notion of science learning requiring nothing more than play, for example in nature (Erickson \& Ernst, 2011; Eshach \& Fried, 2005). This notion might drive the relatively low requirements for preschool instructors to learn science ahead of placement (U.S. Bureau of Labor Statistics, 2021). On the other hand, there are concerns that preschool classrooms might not be set up in a way that is conducive for science learning (Gerde et al., 2018). This is especially evident when science materials or designated science areas are missing $(\mathrm{Tu}, 2006)$.

Even the debate about whether young children can learn science constructs remains unresolved. On the one hand, there is great excitement about the potential of early science learning, based on the idea that children are natural scientists (e.g., Gopnik et al., 1999; Metz, 1995). On the other hand, science is known to be notoriously difficult, eliciting misconceptions and exasperating students in higher grades (e.g., Chi \& VanLehn, 2012; Sawyer, 2006; Vosniadou, 2009). Indeed, scholars have raised concerns about the fact that preschoolers and kindergarteners show little improvement in science achievement after participating in science readiness programs (Greenfield et al., 2009; Saçkes et al., 2010).

These points of tension - whether on learning readiness, long-term benefits of early science learning, or required resources for preschool science pedagogy-are likely to add uncertainty to the field. At the minimum, points of tension might undermine efforts to make science a central part of early learning. For example, open questions on whether young children are cognitively ready to comprehend science constructs hamper curriculum decisions. And open questions on how to best prepare preschoolers for science learning impede the development of teacher-training modules. Thus, to promote scholarly work in the field, points of tension need to be resolved first.

\section{Understanding the Nature of Preschool Science}

One way to respond to tensions in the field is to explore the underlying assumptions that sustain disagreements (Dahl, 2017). In the case of early science learning, one underlying assumption pertains to the nature of preschool science. Those who assume young children are ready for science might intuitively equate preschool science with constructs that can be learned easily at an early age. Vice versa, those who assume protracted learning might intuitively equate preschool science with constructs that are difficult to learn at a young age. Thus, there might be divergent views on what is meant with science at the preschool level. If we could provide data on the nature of preschool science, we could address the tension and therefore contribute to progress in the field.

For questions about the nature of subject matters, important insights can be gained from educational standards. Incidentally, all of the 50 U.S. states put forward recommendations about early science learning (Kloos et al., 2018). They are organized into content domains such as life science, physical science, and earth/space science (e.g., Larimore, 2020; Saçkes et al., 2009). For example, educational standards for preschool science recommend that preschoolers learn about the differences between plants and animals (life science), the properties of light (physical science), and the day-and-night cycle (earth/space science).

To what extent do educational standards recommend science constructs that are difficult for preschool children? The idea is that construct difficulty is central to the question of whether young children can benefit from exposure to science content. If educational standards recommend science constructs that young children can easily learn, we can assume that young children are ready to learn about science. If, on 
the other hand, educational standards recommend science constructs that are difficult for young children, then we can assume that young children are ill-equipped for science learning. Thus, construct difficulty is a relevant dimension by which to characterize the nature of science.

The idea of learning difficulty is fundamental to the field of cognitive development. Indeed, numerous measures have been proposed to capture the learning difficulty of concepts, including relational complexity (Andrews \& Halford, 2002), feature density (Gentner \& Kurtz, 2005; Kloos \& Sloutsky, 2008), or hierarchical position (Kloos et al., 2019; Rosch, 1978). Most prominent is the distinction between concrete and abstract concepts (Crain, 2015; Flavell, 1982; Piaget \& Inhelder, 1969). Concrete concepts can be learned easily because they represent the immediate here-and-now. Abstract concepts, on the other hand, require a cumbersome form of integrating otherwise separate pieces of information (Chambers, 1991; Dumontheil, 2014; Huitt \& Hummel, 2003).

The distinction between concrete and abstract constructs fits well within the realm of science constructs. Learning about different body parts, for example, could be thought of as concrete: Students merely need to attend to obvious entities (e.g., "head," "shoulders"). Learning about the differences between plants and animals, on the other hand, could be thought of as abstract: Students have to attend to potentially hidden features (e.g., the ability of an entity to self-propel), while ignoring superficial but highly salient features (e.g., the color and size of an entity). Learning about constructs such as the properties of light or the day-and-night cycle could also be thought of as abstract: Students need to keep track of events over time and detect a common thread among them. Thus, the distinction between concrete and abstract constructs can be useful for examining the nature of preschool science.

\section{Overview of The Current Research}

The goal of the current study was to explore the difficulty of science constructs specified in educational standards. To do so, we carried out a content analysis of the educational standards put forward by the U.S. states. A content analysis is a systematic way of analyzing text in which the relative presence of target concepts can be determined (DeCuir-Gunby et al., 2011; Dinçer, 2018; Eğmir et al., 2017; Krippendorf, 1989; Larson \& Rahn, 2015). In Study 1, we focused specifically on scientific inquiry: the process by which science knowledge is developed (e.g., "doing science"; Seefeldt \& Galper, 2007). In Study 2, we focused on science facts: the established insights that make up the corpus of science knowledge (e.g., "content knowledge"; Guo et al., 2015). In each case, we asked whether young children are expected to learn about abstract (i.e., difficult) science constructs.

\section{Study 1: Abstraction in Inquiry}

Are preschool children expected to engage in the types of inquiry activities that require abstract thought? To answer this question, we first developed a coding system that could capture the abstraction level of different forms of inquiry. We then applied the identified codes to the U.S. educational standards.

\section{Method}

\section{Preparation of content}

The documents used in our content analysis were the publicly available U.S. readiness standards for science learning in preschool. These standards consist of bullet points in lists, charts, and diagrams, organized by headings and subheadings. Given the inconsistencies between headings across states, we opted to omit them, focusing instead on the bullet-point entries. To be included in the content analysis, a bullet-point entry had to be targeted for children between 36 to 60 months of age. The entry also had to be listed in a section labeled as science (or under similar headings, such as STEM).

Once bullet-point entries were isolated $(N=1060)$, we delineated them into individual items. Each item contains a separate science requirement for preschool science. In most cases, one bullet-point entry corresponded to one item. However, when a bullet-point entry contained multiple sentences that included separate requirements, the entry was split into multiple items. We split 17 bullet-point entries in this way. 
Are preschoolers expected to learn difficult science...

Next, we identified the inquiry terms of each item. Inquiry terms are the phrases that capture an inquiry activity. This could pertain to single verbs (e.g., "observe"), or it could pertain to entire verb phrases (e.g., "make a prediction").

In the process of identifying inquiry terms in items, we encountered action terms that were only tangentially related to science. Such terms focused on engineering (e.g., building something), math (e.g., counting), or the like. We refer to these terms as non-science terms (see Appendix A.1 for detailed information about the codes for non-science terms). Items that consisted entirely of non-science terms, without any scientific inquiry terms, were excluded. The final number of items included in our content analysis was 959 (range per state: 4 to 38 items).

\section{Coding Scheme}

The coding scheme we developed for inquiry terms contained nine codes, ranging from lowest to highest level of abstraction (see Table 1 for a summary). Our scheme drew on two theoretical frameworks: The Scientific Method (i.e., the guide to the development of scientific theories; Gerde et al., 2013) and Bloom's Taxonomy (i.e., a list of activities, organized hierarchically to lead to increasingly deeper learning; Airasian et al., 2001; Hepburn \& Andersen, 2021). Below, we explain each code and the rationale for its assigned level (see Appendix A.2 for additional details on how each inquiry term was coded).

Table 1. Levels of scientific inquiry

\begin{tabular}{lll}
\hline Level & Category & Description \\
\hline 1 & Observe-without-tools & Uses senses to observe what is most salient \\
2 & Observe-with-tools & Uses tools to enhance senses when noticing what is most salient \\
3 & Communicate-without-tools & Communicates understanding, thoughts, etc. in verbal or nonverbal ways \\
4 & Communicate-with-tools & Uses tools such as graphs to communicate thoughts \\
5 & Ask-questions & Expresses confusion or interest about missing information \\
6 & Compare-contrast & Recognizes similarities and differences between entities \\
7 & Predict & Makes an informed guess based on previous experience or understanding \\
8 & Test-a-prediction & Experiments with variables to test hypotheses \\
9 & Explain & Generate explanations for why and how things happen \\
\hline
\end{tabular}

\section{Low Abstraction}

At the lowest degree of abstraction (Levels 1-2), inquiry codes pertain to observing the surroundings. Our thinking was that observations require very little abstraction, if any: Children merely have to look at what is most salient in front of them, without needing to imagine hidden connections. Here, we distinguished between the observe-without-tools code (Level 1) and the observe-with-tools code (Level 2). Example tools for observation include magnifying glasses, microscopes, or measuring cups. The idea was that observations with tools require children to bridge between what entities look like when perceived with tools versus without them, which increases the level of abstraction compared to mere observations.

\section{Medium Abstraction}

At a medium degree of abstraction (Levels 3-5), inquiry codes pertain to communicating about the surroundings. Here, we distinguished between communicating with or without tools, as well as asking questions. Specifically, the communicate-without-tools code (Level 3) pertains to activities such as identifying or recognizing entities (e.g., "know vocabulary"), describing or talking about events ("recall"), or responding to prompts (e.g., "answer questions," "give examples," "confirm"). This code also includes action phrases that refer to more specific forms of communication (e.g., "use evidence," "offer critiques," "interpret observed events") and non-verbal communication (e.g., "draw," "take pictures," "record data").

The communicate-with-tools code (Level 4) applies when specific tools are listed to enhance communication (e.g., "create graphs," "tally observations," "use models of what is observed," "create displays"). Our thinking was that the use of these tools requires children to organize information in ways that are more abstract than merely retelling unorganized information. The ask-questions code (Level 5) applies when the activity of communicating requires children to make connections between what they 
already know and what they do not yet know (e.g., "be curious," "show interest," "express wonder"). Here, our thinking was that the activity of asking questions requires an awareness of something that is missing, which makes it more abstract than merely talking about available information.

\section{High Abstraction}

Finally, at the highest degree of abstraction (Levels 6-9), inquiry codes pertain to identifying, integrating, or manipulating variables. Here, we distinguished between comparing and contrasting entities, making or testing predictions, and generating explanations. Specifically, the compare-contrast code (Level 6) applies to activities in which one or more variables have to be identified against the backdrop of irrelevant aspects (e.g., "analyze data," "sort"). Adding a layer of abstraction, the predict code (Level 7) involves anticipating events in the future by drawing inferences from current circumstances (e.g., "formulate a hypothesis," "make guesses").

Adding yet another layer of abstraction, the test-a-prediction code (Level 8) applies to activities in which a variable has to be manipulated to determine its relation to another (e.g., "test hypotheses," "verify predictions"). This requires not only identifying variables, but also creating a setting in which an otherwise hidden relation between variables can be uncovered. Finally, the explain code (Level 9) applies to activities in which the relation between variables is supplemented with a narrative that goes beyond the immediately available findings (e.g., "make conclusions," "generalize"). This activity is arguably the pinnacle of scientific inquiry: It requires the detection of an otherwise invisible causal chain among variables.

\section{Unspecified Terms}

In addition to the nine abstraction levels, we also identified action phrases that were too vague to apply to a unique abstraction level. An example of such a term is to "explore": This activity could refer to something as concrete as observing the surroundings (Level 1), or to something as abstract as designing an experiment to test a prediction (Level 8). Thus, this term could not be assigned a code unambiguously (consider also "become familiar," "develop an awareness," "learn"). Given this ambiguity, we established an unspecified code for these terms.

\section{Coding Procedure}

Coding of action phrases was carried out iteratively: It started with an initial definition of codes, which was given to two coders who reviewed the items independently from each other. Disagreements were then discussed, resulting in a revision of the code definitions to either adjust or clarify the codes. In the final iteration, three coders reviewed the database of coded items and checked each item's codes independently from the other coders. Disagreement was then discussed a final time, again resulting in adjustments to the coding scheme. Given the consensus approach taken to discussions at each iteration, all items yielded $100 \%$ agreement.

\section{Results}

Results are presented in three sections: The first section provides general information about how the educational standards differ among states. We then consider the broad distinction among the three degrees of abstraction (low, medium, high). Finally, we look more specifically at the prevalence of the four codes at the highest degree of abstraction.

\section{Differences Among States}

We found numerous ways in which state standards differed, starting with the number of items they listed: Some states had as few as 4 items, while others had over 20 items (see Appendix B.1 for the number of inquiry items and terms by state). Items also differed in their length: While some items consisted of just 2 words, others contained more than 20 words. The specificity of the content differed, too. While some items were vague (e.g., "use senses to experience something and make one or two comments to describe this"), others provided explicit examples (e.g., "observe processes and relationships, for example by using measuring cups to measure fish food, then observing fish and recording how much they eat"). 
State standards also differed in what kind of inquiry they required of preschoolers. For example, while most standards used relatively few unspecified inquiry terms, some standards used primarily unspecified inquiry terms (6\%). More to the point of abstraction levels, while some state standards covered every one of the nine abstraction levels $(6 \%)$, other state standards restricted themselves to no more than three abstraction levels (10\%). Figure 1 shows the prevalence of each abstraction code, separated by state.

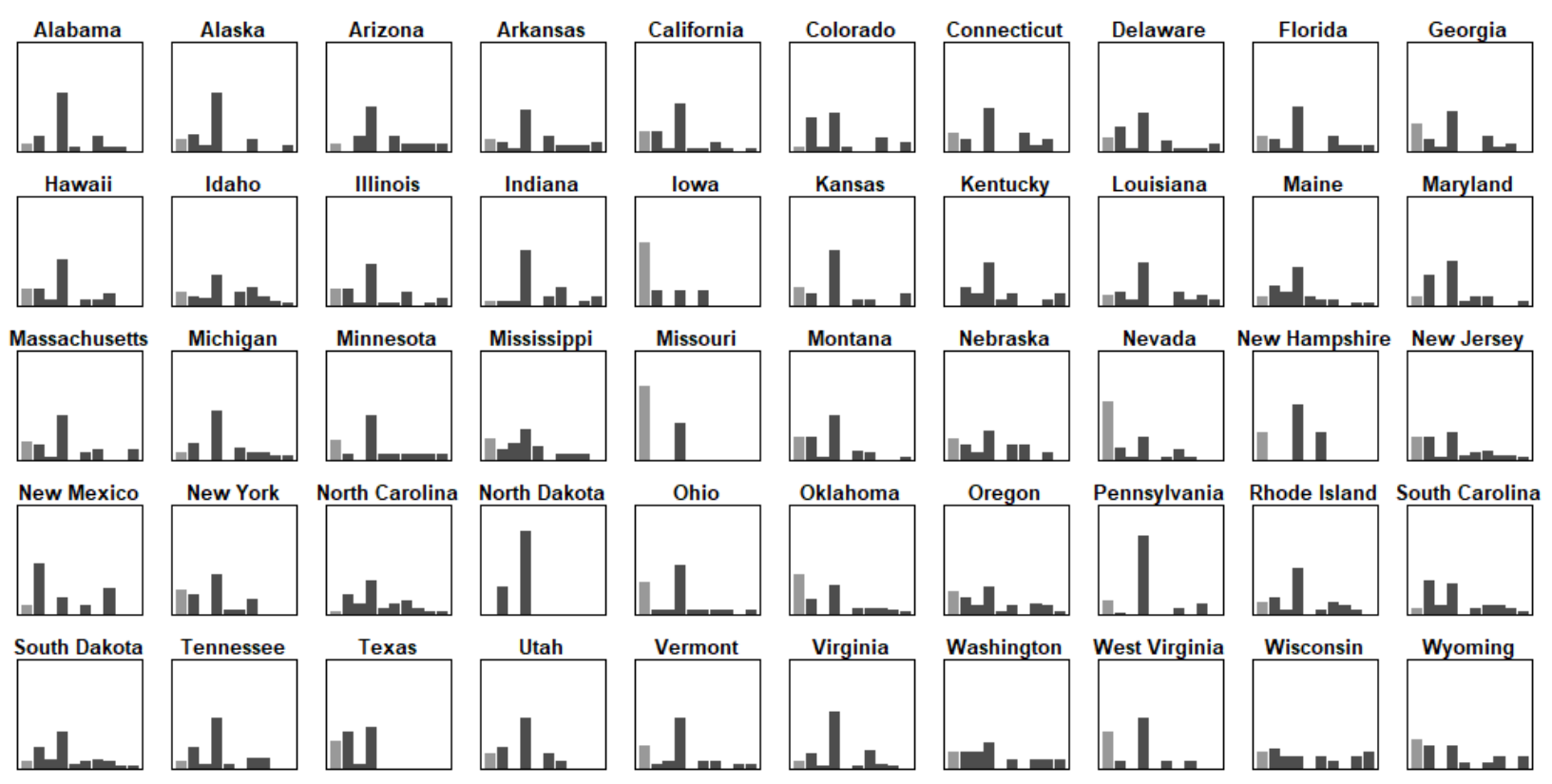

Note. Light bars show the proportion of unspecified inquiry terms. Dark bars show the proportion of specified inquiry terms. The specified inquiry terms include: observe-without-tools, observe-with-tools, communicate-without-tools, communicate-with-tools, ask-questions, compare-contrast, predict, test-a-prediction, and explain. The specified inquiry terms are ordered from lowest to highest abstraction level.

Figure 1. Inquiry terms by state

We calculated an average abstraction level for each state, building on the idea that the nine levels of abstraction are ordered from lowest to highest. Specifically, we first calculated an average abstraction score for each item, and then we averaged across those scores for each state (excluding unspecified terms). Figure 2 shows the obtained results: While some state standards recommended inquiry at relatively high levels of abstraction (over $4.00,20 \%$ of standards), the abstraction levels for inquiry recommended in other state standards was low (under $3.00,4 \%$ of standards). 


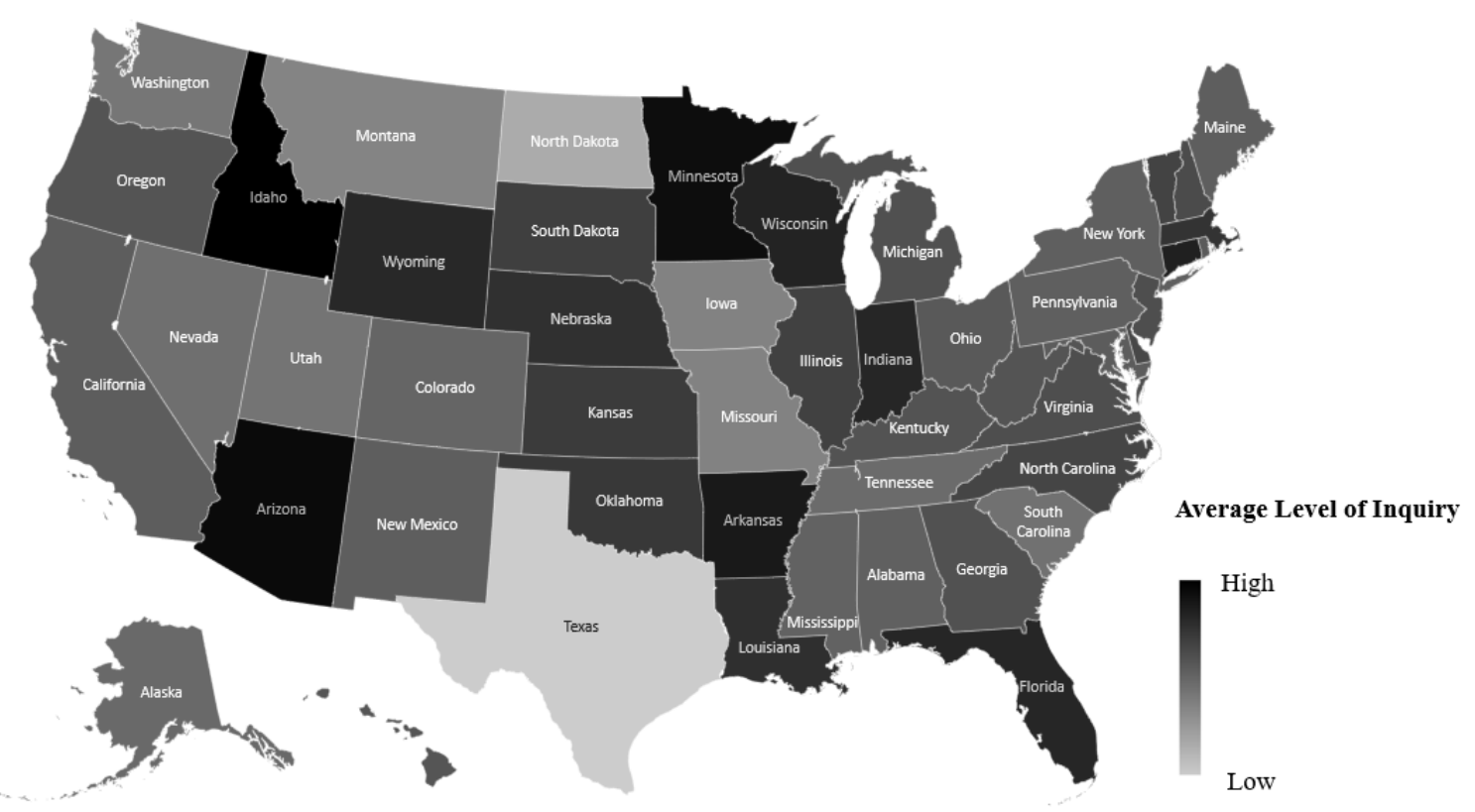

Note. The lowest possible score was 1 (observe-without-tools), and the highest possible score was 9 (explain). State averages range from 2.06 ("Low") to 4.65 ("High”).

Figure 2. Map of average abstraction level

\section{Broad Contrast Among Degrees of Abstraction}

Next, we sought to capture broad trends across the U.S. standards. To do this, we calculated the proportion of inquiry terms that were of low (i.e., observing phenomena), medium (i.e., communicating about science), and high degrees of abstraction (i.e., attending to variables) and averaged them across states. Figure 3 presents the obtained results: The most common inquiry terms were at a medium degree of abstraction $(M=46 \%, S D=12.16)$. Inquiry terms at the low degree of abstraction were less prevalent $(M$ $=19 \%, S D=9.76)$. They matched in prevalence with the high-abstraction inquiry terms $(M=18 \%, S D=$ 9.00).

Many state standards (44\%) followed the overall pattern found across the U.S. states: Many featured a large number of medium-abstraction codes, and many featured approximately equal numbers of lowand high-abstraction codes. Thus, high-abstraction inquiry, while not the most prevalent, was nevertheless prominently featured in the educational standards-as prominent as low-abstraction inquiry. In fact, nearly all state standards (90\%) required at least some high-abstraction inquiry. Considered together, highabstraction codes accounted for $23 \%$ of the total specified inquiry terms.

\section{Specific Contrast Among High-Abstraction Codes}

Finally, we sought to provide details on the type of inquiry required at the high end of the abstraction spectrum (compare-contrast, predict, test-a-prediction, explain). Figure 4 provides these data averaged across state standards. Of the four types of high-abstraction codes, the compare-contrast code was most prevalent $(42 \%)$, occurring approximately twice as often as each of the other three types of high-abstraction codes. Indeed, this is the most prevalent of the high-abstraction codes for many states (54\%), and most states feature at least one compare-contrast term $(87 \%)$. The most common inquiry terms from this category were "differentiate" and "categorize." 
Are preschoolers expected to learn difficult science...

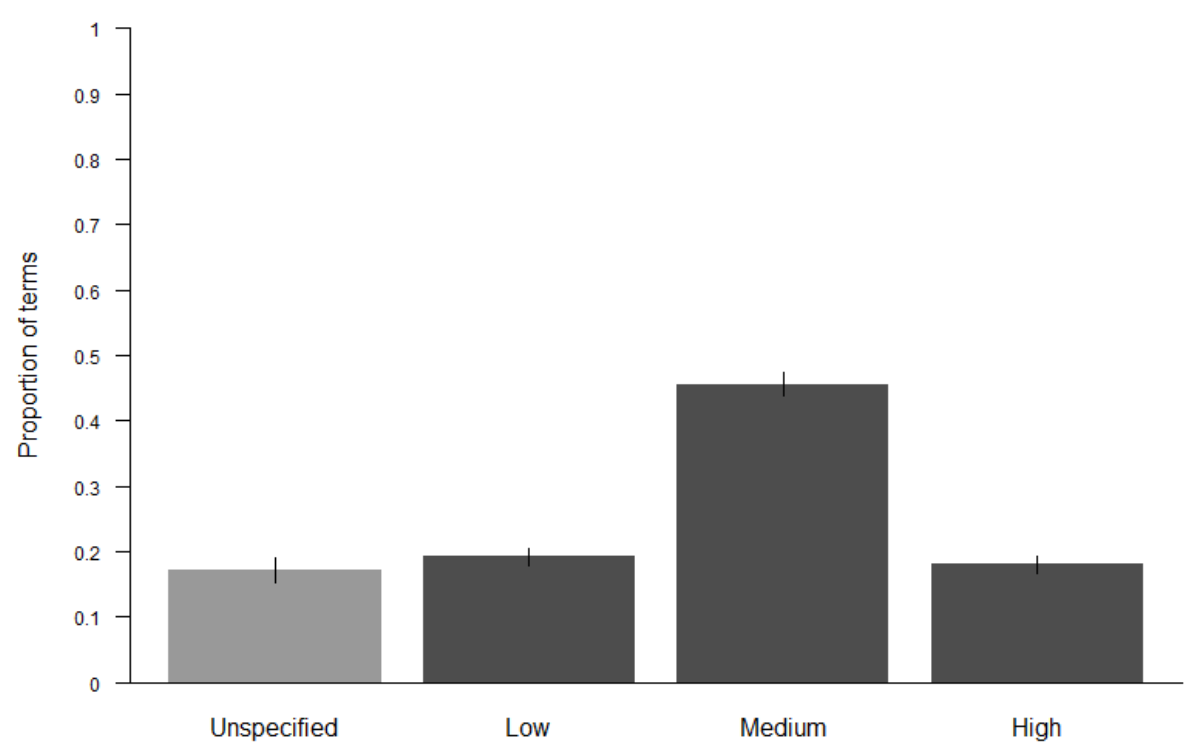

Note. Proportions were averaged across states. The light bar shows the average proportion of unspecified terms. The dark bars show the average proportions of specified terms (low, medium, or high degree of abstraction). Error bars represent the standard error of the mean.

Figure 3. Average Proportion of Inquiry Terms

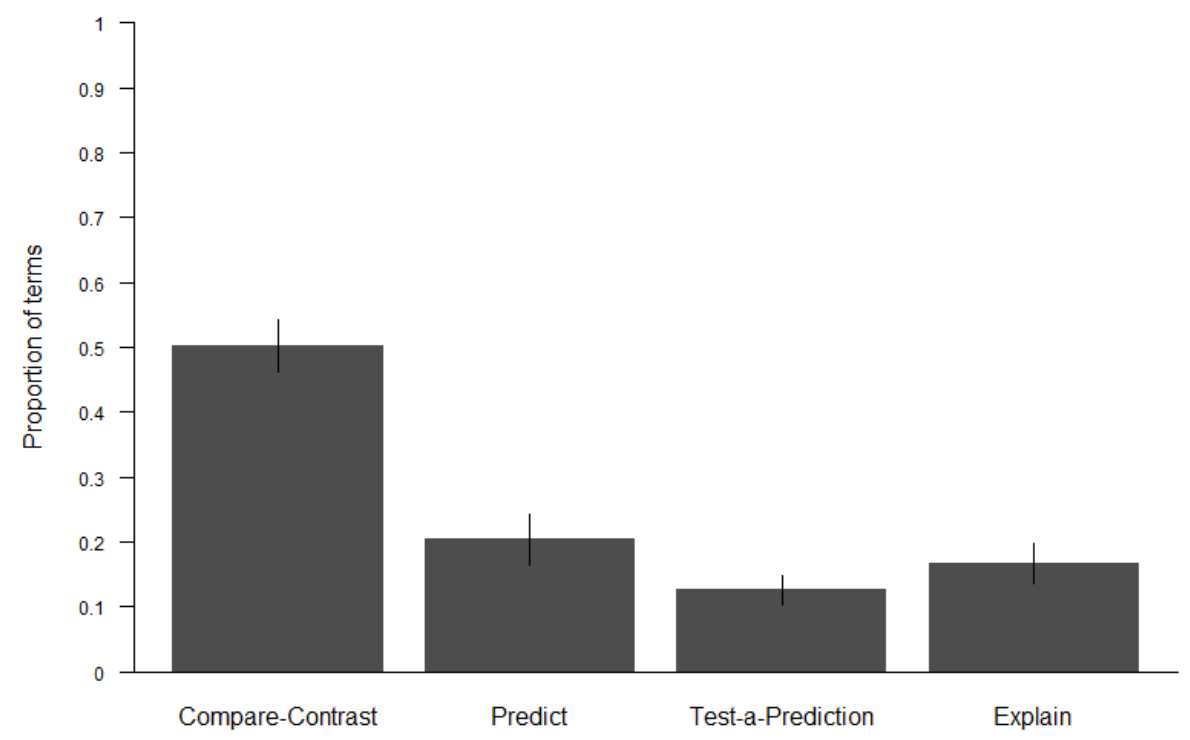

Note. Proportions were averaged across states. Error bars represent standard errors of the mean.

Figure 4. Proportion of high abstraction inquiry terms

The other three types of high-abstraction codes, though less prevalent than the compare-contrast code, were nevertheless represented in many state standards. For example, the predict code appeared at least once in $67 \%$ of the states. The most common terms of this type of abstraction were "hypothesize" and "anticipate". Likewise, the test-a-prediction code appeared at least once in $64 \%$ of the state standards. The most common terms of this type of abstraction were "test hypotheses" and "experiment." Even the highest level of abstraction, the explain code, appeared in many states at least once (67\%). The most common terms of the explain code were "explain" and "generate conclusions." 


\section{Discussion}

In Study 1, we sought to characterize the level of abstraction present in scientific inquiry. Our results show that abstract scientific inquiry is indeed expected in U.S. preschools, at least to some extent. We found that the most prevalent inquiry activity is that of communicating. On some level, this might be expected, given that children's communicative behavior allows teachers to gauge their students' understanding (Brenneman, 2011). At the same time, this type of inquiry - to recognize things, learn science vocabulary, and discuss observations - is far from trivial for young children. Further, state standards were largely consistent in requiring high degrees of abstraction in inquiry. In fact, many standards specified that young children should engage in all levels of high-abstraction inquiry, including to test predictions and formulate explanations.

\section{Study 2: Abstraction in Science Facts}

In Study 2, we sought to characterize the level of abstraction present in science facts. That is to say, we asked whether preschool children are expected to learn about abstract content in the corpus of established scientific knowledge. To answer this question, we developed a coding system to capture abstraction in science facts and then applied it to the educational standards that contained facts.

\section{Method}

\section{Preparation of content}

To prepare the content of this analysis, we started with the 959 science items used in Study 1. First, we identified the domain of science that each item belonged to. Our rationale was that scientific facts can be analyzed best if they are specific enough to fit within a domain of science. Or, put differently, if content cannot be attributed to a domain of science, then it is likely to be too vague to allow a designation of concrete versus abstract content. Domains of science pertained to topics such as life science (e.g., biology), physical science (e.g., physics), or earth/space science (e.g., astronomy). Some items were coded as other science (e.g., social science, environmentalism) or multiple sciences (e.g., a combination of domains). Appendix A.3 provides details on how the domains of science were defined.

We excluded a total of 271 items that either had no content at all ( $n=188$, e.g., "discuss predictions"), were too vague to attribute to a specific domain of science $(n=74$, e.g., "collect data"), or were too general to determine their abstraction level ( $n=9$, e.g., "understand life science"). We conducted the content analysis with the remaining 688 items (range per state: 1 to 44 items).

\section{Coding Scheme}

To capture the abstraction level of science facts, we distinguished between concrete and abstract facts. Specifically, concrete facts were defined as those that are readily perceivable, without having to connect any pieces of information. Examples of concrete facts are visible physical properties (color, size, material) or obvious events (e.g., sinking). We also included facts that could be observed directly (e.g., sound, light, shadow), as long as there was no explicit requirement to understand the source of those phenomena. References to vocabulary, rules, or functions were also treated as concrete, since this information merely needs to be memorized.

Abstract facts, on the other hand, refer to information that is hidden and thus requires some mental effort to access. Consider, for example, the construct of "family." For a group to be family, there have to be unique relations among the members of the group. These relations cannot be reduced to a physical property or a salient event. Instead, individual pieces of information must be integrated into a coherent whole to arrive at the construct of "family."

For abstract facts, we distinguished between relations, patterns, groups, and forces (see Appendix A.4 for detailed information about these codes). The relations code captures connections between entities, whether the connection is causal ("effect," "impact," "control"), correlational ("interaction," "heredity"), 
Are preschoolers expected to learn difficult science...

or based on dependency (e.g., "protect," "preserve"). The patterns code captures events that unfold over time (e.g., "life cycle," "transformation," "motion"). The groups code captures distinctions between entities that are based on hidden characteristics or traits ("living vs. nonliving things"). And the forces code captures references to causal properties (e.g., "gravity," "magnetism," "buoyancy," "energy").

Note that the abstract categories of relations, patterns, groups, and forces are interrelated. For example, all relations are also patterns, and all forces are also relations. To distinguish codes consistently, we chose to base our coding scheme on individual words or phrases. For example, the item "describe the effects of forces in nature" received the code of relations (because of its reference to cause-effect relations) as well as the code of forces (because it invoked the term "force").

Note also that concrete terms were sometimes nested within abstract phrases. For example, the phrase "the effects of an action on an object" consists of both an abstract code (a causal relation) and a concrete code ("an object"). In cases like this, we coded both the abstract and the concrete part of the phrase. As a result, some items contained both concrete and abstract terms (vs. items that consisted entirely of concrete terms or items that consisted entirely of abstract terms).

\section{Coding Procedure}

Coding followed the same iterative process that was used in Study 1. We first drafted initial definitions of codes and then refined them through subsequent rounds of coding and discussion. Specifically, we identified all the fact phrases and determined whether each one was concrete or abstract (and, in the latter case, whether it falls into the category of relations, patterns, groups, or forces). In each round, two independent coders went through the items and coded them, then came together to discuss the disagreements and refine the definitions of the codes.

While all disagreements could be resolved during the aforementioned iterative process, one item provoked repeated discussion: "Recognize that everything is made of matter." Going by majority decision, this item was ultimately coded as groups, the argument being that the item was indicative of an underlying trait (i.e., everything has the hidden characteristic of matter).

\section{Results}

Results are presented in three sections: The first section focuses on the variability among state standards. We then consider the broad contrast among items that contained only concrete terms, concrete and abstract terms, or only abstract terms. Of interest was the relative prevalence of each type of item (concrete-only, concrete-and-abstract, abstract-only) as a function of the domain of science. Finally, we look more specifically at the four types of abstract facts (relations, patterns, groups, forces) and explore their relative prevalence in each domain of science.

\section{Differences Among States}

Similar to Study 1, there were several differences across state standards (see Appendix B.2 for the number of fact items and terms by state). For example, while some standards included information about science facts for virtually all of their items (20\%), others provided far fewer facts. There was even a difference in the number of facts per specified item, ranging from one to four facts per item. State standards also differed in the domain of science that was covered. For example, while some standards did not include any life-science items (16\%), other standards featured them prominently. We found similar variability with physical science: While one state standard was comprised exclusively of physical-science items, two standards had none at all.

We also found differences in the degree to which the standards recommended abstract versus concrete facts (see Figure 5 for the profiles of each state standard, separated by types of items and types of facts). For example, two state standards consisted entirely of concrete items. And, while abstract content presumably builds upon concrete foundations, 38\% of state standards nevertheless featured at least one exclusively abstract item. And, concerning the different types of abstract facts (relations, patterns, groups, 
forces), many standards featured at least three types of abstraction (46\%). Eight standards listed all four types of abstraction, while four only had one primary abstraction code.

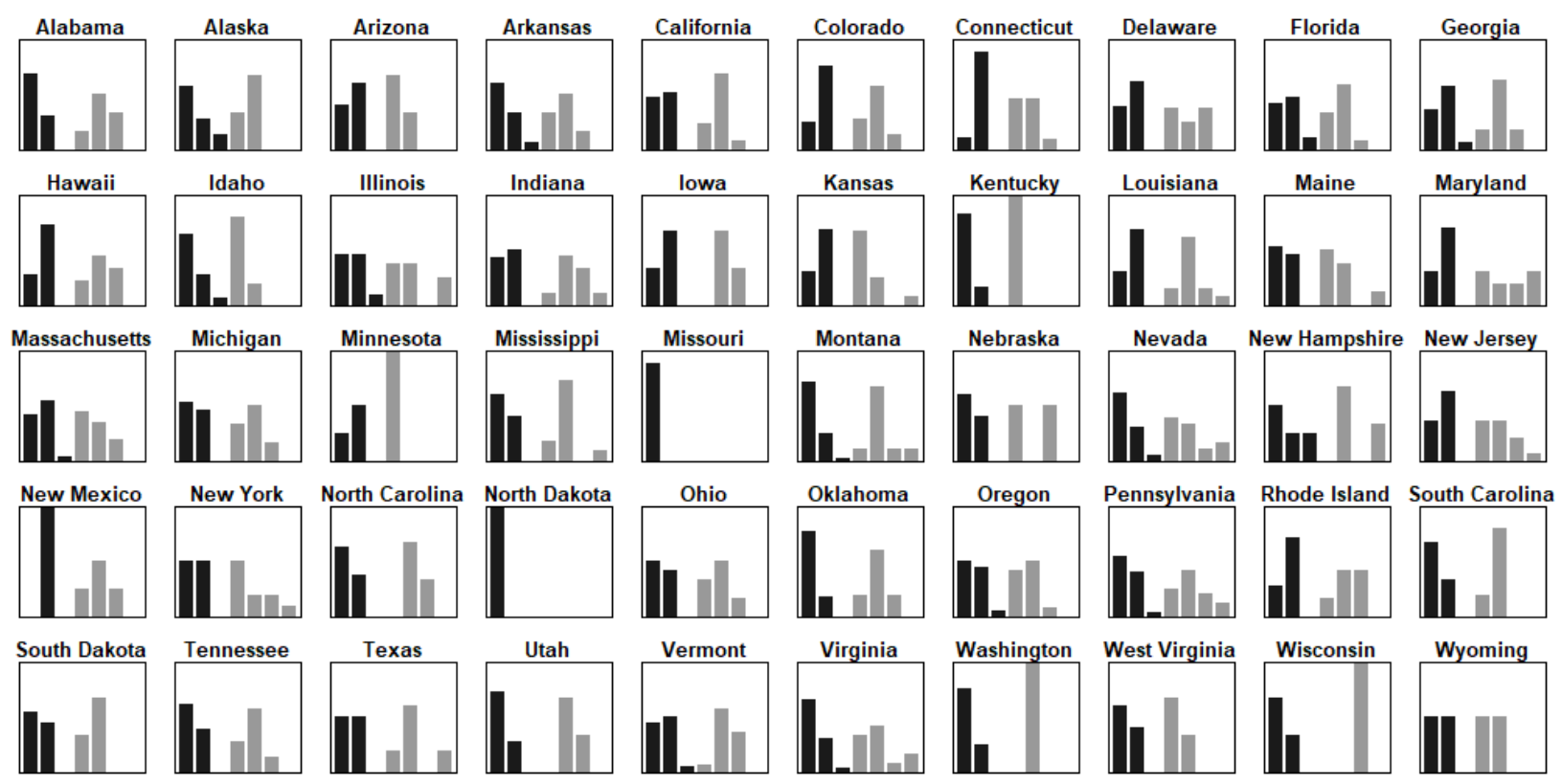

Note. The dark bars show the proportion of each type of item (concrete-only, concrete-and-abstract, abstract-only). The light bars show the proportion of each type of abstract fact term (relations, patterns, groups, forces).

Figure 5. Proportion of types of items and terms by state

\section{Broad Contrast Among Different Items}

Recall that an item could have concrete terms, abstract terms, or a combination of both (e.g., when concrete terms were nested within abstract terms). Table 2 displays the relative prevalence of each of these types of items. Results show that only $2 \%$ of the items had exclusively abstract content. This holds for the individual domains of science as well: The prevalence of abstract-only items ranged from $0 \%$ (multiple sciences) to $4 \%$ (earth/space science; other science).

At the same time, when considering whether items had at least some abstraction (i.e., abstract-only or concrete-and-abstract), the proportion of items with at least some abstract content is sizable ( $47 \%$ across domains). Using Generalized Linear Mixed-Effects Models (GLMMs) (Hox, 2010) to compare relative frequencies, we found that the presence of abstract content did not differ across science domains, $D(4)=$ $5.00, p=.287$. Almost half of the items in life science (45\%), physical science $(50 \%)$, and earth/space science (49\%) featured abstract facts.

\section{Specific contrast among abstract codes}

Table 2 also shows the relative prevalence of the different types of abstract codes (relations, patterns, groups, forces). The forces code was the least common across the domains of science, found in only $6 \%$ of abstract fact phrases. Even within physical science, arguably the natural home of force-related concepts, only $14 \%$ of fact phrases referred to forces. The groups code was also relatively uncommon, occurring in only $16 \%$ of the abstract fact phrases. Here, we found a difference in proportion by domain, $D(4)=32.35, p$ $<.001$, with life science being the domain with the most groups codes, post-hoc Wald test $W \mathrm{~s}(1)>4.75$, $p \mathrm{~s}<$ .029. A typical example of this code was to "categorize common living things as either plants or animals."

Table 2. Proportion of types of items and types of abstract terms within each science domain

\begin{tabular}{|c|c|c|c|c|c|c|}
\hline \multirow{2}{*}{ Level of Abstraction } & \multicolumn{5}{|c|}{ Domain of Science } & \multirow[b]{2}{*}{ Total } \\
\hline & Life & Physical & Earth/Space & Other & Multiple & \\
\hline \multicolumn{7}{|l|}{ Types of Items } \\
\hline Concrete Only & $55 \%$ & $50 \%$ & $51 \%$ & $62 \%$ & $47 \%$ & $52 \%$ \\
\hline Concrete \& Abstract & $44 \%$ & $46 \%$ & $45 \%$ & $32 \%$ & $51 \%$ & $44 \%$ \\
\hline
\end{tabular}


Are preschoolers expected to learn difficult science...

\begin{tabular}{lcccccc}
\hline Abstract Only & $<1 \%$ & $3 \%$ & $4 \%$ & $4 \%$ & - & $2 \%$ \\
Types of Abstract Terms & & & & & & \\
Relations & $25 \%$ & $32 \%$ & $13 \%$ & $83 \%$ & $33 \%$ & $31 \%$ \\
Patterns & $46 \%$ & $46 \%$ & $76 \%$ & $14 \%$ & $28 \%$ & $47 \%$ \\
Groups & $28 \%$ & $8 \%$ & $10 \%$ & $3 \%$ & $37 \%$ & $16 \%$ \\
Forces & $1 \%$ & $14 \%$ & - & - & $2 \%$ & $6 \%$ \\
\hline
\end{tabular}

The patterns code was more prevalent than that of forces and groups, found in $47 \%$ of the fact terms. Here too, we found a difference in proportion by domain, $D(4)=42.02, p<.001$, with earth/space science being the domain with the most patterns codes $(76 \%)$, Wald test $W \mathrm{~s}(1)>3.58, p \mathrm{~s}<.058$. One of the most common patterns constructs in this domain were cycles, such as the day/night and water cycles. Patterns were also common in the domains of life science and physical science, found in $47 \%$ of the abstract fact terms of each of these domains. Typical examples were growth over time (life science) and the motion of objects (physical science).

Finally, the relations code was of intermediate prevalence, found in $31 \%$ of the fact phrases across domains. Finding a difference by domain, $D(4)=25.36, p<.001$, relations were most common in the physicalscience domain $(32 \%)$. For this domain, the most common relations construct was cause and effect (e.g., "cause and effect of pushing/pulling objects"). In contrast, relations were less common in the life-science domain $(25 \%), W(1)=5.78, p=.016$, and even rarer in the earth/space science domain $(13 \%), W(1)=10.45, p$ $=.001$. Typical examples were interactions between living things and their environments (life science) and how weather relates to seasons (earth/space science).

\section{Discussion}

Are preschool children expected to attend to and learn about science facts that require abstract thought? Like with abstract inquiry in Study 1, we found that this is indeed the case: About half of the items assessed in the content analysis featured at least one abstract fact, regardless of science domain. Specifically, preschool children are expected to pay attention to patterns that unfold over time, most notably in the domain of earth/space science. They are also expected to pay attention to relations, for example when asked to think about humans and nature. They were even expected to pay attention to forces, though to a lesser degree than to relations or patterns.

\section{General Discussion}

Our work was motivated by a noticeable dip in the amount of scholarly work on early science learning. While we cannot claim to know the sources of this decline, there are several points of tension in the field that might hamper progress. In fact, there appear to be unresolved questions regarding whether young children are able to learn science constructs at all. Our paper was designed to address unresolved issues by looking more specifically at the difficulty level of the science constructs recommended for preschool.

Our results show that recommended science constructs vary widely in learning difficulty. Regarding inquiry, for example, most educational standards recommend something as simple as observing the surroundings with one's own senses. At the same time, they also recommend something as sophisticated as formulating and testing explicit hypotheses. Even the activity of generating explanations is common in the educational standards. A similar pattern emerges with science facts: While many standards recommend knowing something as obvious as the names of body parts, they also recommend knowing about patterns that evolve over time, such as the lifecycles of animals. Thus, preschool science is neither difficult nor easy: It is both.

Given the variability in learning difficulty of recommended science concepts, a conclusive "yes-orno" answer to the question of whether young children can learn science is perhaps not sensible: Young children are cognitively ready to comprehend some, but not all, science constructs. That is to say, before an 
answer can be provided about classroom organization, teacher preparation, or pedagogy, more information about the difficulty level of the desired science construct is needed. When science constructs are concrete, young children can learn them spontaneously, merely via play (e.g., observing the surrounding). In contrast, when science constructs are abstract (e.g., making predictions; understanding the impact of gravity on objects), spontaneous play in the everyday surrounding is no longer enough to promote learning.

Still, learning about abstract science constructs is possible for young children. Research has shown that preschoolers can reason abstractly, such as when testing a hypothesis or reaching a conclusion (Bonawitz et al., 2011; French, 2004; Sobel \& Legare, 2014; Sodian et al., 1991; Trundle \& Smith, 2017). To be able to do this, however, children need exposure to a setting that highlights otherwise hidden links. For example, in order to formulate and test a hypothesis, the relevant variables need to be more salient than irrelevant variables (Kloos et al., 2019). In a typical preschool classroom, such order is unlikely to be present (e.g., Fisher et al., 2013; Kirschner et al., 2006). Thus, learning about abstract science constructs requires a change in the everyday preschool setting.

Research has indeed identified some strategies that might be helpful for acclimating young children to abstract science concepts. For example, prompting children to document their observations and talk about observed similarities and differences is a feasible and effective strategy to highlight what might otherwise remain hidden (e.g., Brenneman \& Louro, 2008; Fleer, 1991; Fleer \& Beasley, 1991). Similarly, the use of schematic representations such as concept maps or conceptual models can help young children see how entities or events are related (e.g., Gobert \& Buckley, 2000; Hunter et al., 2008; Kenyon et al., 2008; Novak, 2010; Wiser \& Smith, 2008). Incidentally, we found that the educational standards only rarely recommended the use of tools to visualize otherwise hidden relations.

Regarding preschool teachers' apprehension about incorporating science into the general curriculum, our findings highlight the importance of specifying the degree of difficulty of the chosen science constructs. Vaguely phrased science items could give practitioners some leeway in their curriculum choices. For example, teachers who are unsure about science pedagogy could focus on science constructs that can be learned spontaneously during children's play (i.e., concrete science constructs). At the same time, the lack of specificity is likely to put a heavy burden on teachers to come up with ways of organizing their science curricula. The solution is to work out a clear definition of science and recommend a sensible ordering from lower- to higher-abstraction constructs - which is currently missing from the educational standards.

\section{Conclusion}

Even though the field of early science learning has enjoyed increased attention over the decades, fundamental disagreements remain, such as about whether young children are capable of learning science. Our findings put important constraints in place to address this disagreement. Specifically, we found that scientific inquiry and scientific facts recommended at the preschool level vary considerably in difficulty. This suggests that the question of whether children can learn science depends on how difficult the particular science construct is. Young children might be able to easily learn salient science constructs from exposure alone. For more hidden science constructs, however, a more intentional effort might be needed to support preschoolers' learning.

Our findings also highlight an important gap in the field of early science learning: that there is no universally accepted definition of science at the preschool level. For example, while state recommendations largely agree on including both concrete and abstract science constructs, there are numerous differences among the existing recommendations. Without a clear definition of early science, research on science learning is necessarily confined to the idiosyncratic definitions adopted by each research team. In turn, this curtails transferability to the preschool classroom and, thus, has only limited practical relevance for those who operate under a different definition of science. Before early science education can be successful, then, it might first be necessary to adopt a consistent definition of science. 
Are preschoolers expected to learn difficult science...

\section{Declarations}

Acknowledgments: Not applicable

Authors' note: Part of the research presented in this paper was derived from a master's thesis completed by A.O.

Authors' contributions: A.O. and H.K. contributed to all aspects of the work reported here, including the design and implementation of the research, the data analyses and visualization, and the writing and editing of the manuscript. T.W. contributed to the development of the methodology and its implementation, data analysis and visualization, inferential statistics, and some writing and editing of the manuscript. C.C. contributed primarily to the development of the methodology and some data analysis.

Data Availability: The data used in this research, as well as additional supplementary information, are publicly available on the Open Science Framework: https://osf.io/geqnb/

Competing interests: The authors declare that they have no competing interests.

Funding: Not applicable.

\section{Adherence to ethical concerns}

The research reported here does not involve human subjects. The basis for the research was the analysis of records that are publicly available (educational standards).

\section{References}

Airasian, P. W., Cruikshank, K. A., Mayer, R. E., Pintrich, P. R., Raths, J., \& Wittrock, M. C. (2001). A taxonomy for learning, teaching, and assessing: A revision of Bloom's taxonomy of educational objectives (L. W. Anderson \& D. R. Krathwohl, Eds.). Longman.

Andrews, G., \& Halford, G. S. (2002). A cognitive complexity metric applied to cognitive development. Cognitive Psychology, 45(2), 153-219. https://doi.org/10.1016/S0010-0285(02)00002-6

Blonder R., Benny N., \& Jones, M. G. (2014). Teaching self-efficacy of science teachers. In R. Evans, J. Luft, C. Czerniak, \& C. Pea (Eds.), The role of science teachers' beliefs in international classrooms (pp. 3-15). SensePublishers. https://doi.org/10.1007/978-94-6209-557$\underline{1}$

Bonawitz, E., Shafto, P., Gweon, H., Goodman, N. D., Spelke, E., \& Schulz, L. (2011). The double-edged sword of pedagogy: Instruction limits spontaneous exploration and discovery. Cognition, 120(3), 322-330. https://doi.org/10.1016/j.cognition.2010.10.001

Brenneman, K. (2011). Assessment for Preschool Science Learning and Learning Environments. Early Childhood Research $\mathcal{E}$ Practice, 13(1), n1. http://ecrp.uiuc.edu/v13n1/brenneman.html

Brenneman, K., \& Louro, I. F. (2008). Science journals in the preschool classroom. Early Childhood Education Journal, 36(2), 113-119. https://doi.org/10.1007/s10643-008-0258-z

Brenneman, K., Stevenson-Boyd, J., \& Frede, E. C. (2009). Math and science in preschool: Policies and practice. Preschool Policy Brief, 19, $1-12$.

Chambers, J. H. (1991). The difference between the abstract concepts of science and the general concepts of empirical educational research. The Journal of Educational Thought, 25(1), 41-49. http://www.jstor.org/stable/23767703

Chi, M. T., \& VanLehn, K. A. (2012). Seeing deep structure from the interactions of surface features. Educational Psychologist, 47(3), 177-188. http://dx.doi.org/10.1080/00461520.2012.695709

Crain, W. (2015). Theories of development: Concepts and applications. Psychology Press. http://dx.doi.org/10.4324/9781315662473

Dahl, A. (2017). Ecological commitments: Why developmental science needs naturalistic methods. Child Development Perspectives, 11(2), 79-84. https://doi.org/10.1111/cdep.12217

DeCuir-Gunby, J. T., Marshall, P. L., \& McCullochh, A. W. (2011). Developing and using a codebook for the analysis of interview data: An example from a professional development research project. Field Methods, 23(2), 136-155. https://doi.org/10.1177/1525822X10388468

Dinçer, S. (2018). Content analysis in scientific research: Meta-analysis, meta-synthesis, and descriptive content analysis. Bartın Üniversitesi Ĕ̆itim Fakültesi Dergisi, 7(1), 176-190. http://doi.org/10.14686/buefad.363159

Dumontheil, I. (2014). Development of abstract thinking during childhood and adolescence: The role of rostrolateral prefrontal cortex. Developmental Cognitive Neuroscience, 10, 57-76. https://doi.org/10.1016/j.den.2014.07.009

Education.com (2021, July 31). Preschool science lesson plans. https://www.education.com/lesson-plans/preschool/science/

Educational Development Center. (2013). Nurturing STEM skills in young learners, preK-3 (STEM Smart Brief). Successful STEM Education. https://successfulstemeducation.org/resources/nurturing-stem-skills-young-learners-prek\%E2\%80\%933

Eğmir, E., Erdem, C., \& Koçyiğit, M. (2017). Trends in educational research: A content analysis of the studies published in international 


\section{Ana OCASIO et al.}

journal of instruction. International Journal of Instruction, 10(3), 277-294. https://doi.org/10.12973/iji.2017.10318a

Erickson, D. M., \& Ernst, J. A. (2011). The real benefits of nature play every day. Exchange, 33(4), 97-99.

Eshach, H., \& Fried, M. N. (2005). Should science be taught in early childhood? Journal of Science Education and Technology, 14(3), 315336. http://dx.doi.org/10.1007/s10956-005-7198-9

Fisher, K. R., Hirsh-Pasek, K., Newcombe, N., \& Golinkoff, R. M. (2013). Taking shape: Supporting preschoolers' acquisition of geometric knowledge through guided play. Child Development, 84(6), 1872-1878. http://dx.doi.org/10.1111/cdev.12091

Flavell, J. H. (1982). On cognitive development. Child Development, 53(1), 1-10. http://dx.doi.org/10.2307/1129634

Fleer, M. (1991). Socially constructed learning in early childhood science education. Research in Science Education, 21(1), 96-103. http://dx.doi.org/10.1007/BF02360462

Fleer, M., \& Beasley, W. (1991). A study of conceptual development in early childhood. Research in Science Education, 21(1), 104-112. http://dx.doi.org/10.1007/BF02360463

French, L. (2004). Science as the center of a coherent, integrated early childhood curriculum. Early Childhood Research Quarterly, 19(1), 138-149. http://dx.doi.org/10.1016/j.ecresq.2004.01.004

Gentner, D., \& Kurtz, K. J. (2005) Relational categories. In W. K. Ahn, R. L. Goldstone, B. C. Love, A. B. Markman \& P. Wolff (Eds.), Categorization inside and outside the laboratory: Essays in honor of Douglas L. Medin (pp. 151-75). American Psychological Association. http://dx.doi.org/10.1037/11156-009

Gerde, H. K., Pierce, S. J., Lee, K., \& Van Egeren, L. A. (2018). Early childhood educators' self-efficacy in science, math, and literacy instruction and science practice in the classroom. Early Education and Development, 29(1), 70-90. http://dx.doi.org/10.1080/10409289.2017.1360127

Gerde, H. K., Schachter, R. E., \& Wasik, B. A. (2013). Using the scientific method to guide learning: An integrated approach to early childhood curriculum. Early Childhood Education Journal, 41(5), 315-323. http://dx.doi.org/10.1007/s10643-013-0579-4

Gobert, J. D., \& Buckley, B. C. (2000). Introduction to model-based in teaching and learning in science education. International Journal of Science Education, 22(9), 891-894. http://dx.doi.org/10.1080/095006900416839

Gopnik, A., Meltzoff, A. N., \& Kuhl, P. K. (1999). The scientist in the crib: Minds, brains, and how children learn. William Morrow \& Co.

Greenfield, D. B. (2015). Assessment in early childhood science education. In K. C. Trundle \& M. Saçkes (Eds.), Research in early childhood science education (pp. 353-380). Springer. http://dx.doi.org/10.1007/978-94-017-9505-0_16

Greenfield, D. B., Jirout, J., Dominguez, X., Greenberg, A., Maier, M., \& Fuccillo, J. (2009). Science in the preschool classroom: A programmatic research agenda to improve science readiness. Early Education and Development, 20(2), 238-264. http://dx.doi.org/10.1080/10409280802595441

Guo, Y., Piasta, S. B., \& Bowles, R. P. (2015). Exploring preschool children's science content knowledge. Early Education and Development, 26(1), 125-146. http://dx.doi.org/10.1080/10409289.2015.968240

Guo, Y., Wang, S., Hall, A. H., Breit-Smith, A., \& Busch, J. (2016). The effects of science instruction on young children's vocabulary learning: A research synthesis. Early Childhood Education Journal, 44(4), 359-367. http://dx.doi.org/10.1007/s10643-015-0721-6

Hepburn, B., \& Andersen, H. (2021). Scientific method. In E. N. Zalta (Ed.), The Stanford Encyclopedia of Philosophy (Summer 2021 edition). SEP. https://plato.stanford.edu/archives/sum2021/entries/scientific-method/

Hox, J. (2010). Multilevel analysis: Techniques and applications (2nd ed.). Routledge. http://dx.doi.org/10.4324/9781315650982

Huitt, W. \& Hummel, J. (2003). Piaget's theory of cognitive development. Educational Psychology Interactive, 3(2), 1-5. http://chiron.valdosta.edu/whuitt/col/cogsys/piaget.html

Hunter, J., Monroe-Ossi, H., \& Fountain, C. (2008). Young Florida naturalists: concept mapping and science learning of preschool children. In A. J. Cañas, P. Reiske, M. Ahlberg, \& D. Novak (Eds.), Concept maps: Connecting educators. Proceedings of the Third International Conference on Concept Mapping. Tallinn, Estonia \& Helsinki, Finland: University of Finland.

Kachergis, G., Gureckis, T. M., \& Rhodes, M. (2019, July 24-27). Exploring informal science interventions to promote children's understanding of natural categories [Conference presentation]. 41st Annual Conference of the Cognitive Science Society, Montreal, Canada. https://par.nsf.gov/servlets/purl/10200201

Kelemen, D., Emmons, N. A., Schillaci, R. S., \& Ganea, P. A. (2014). Young children can be taught basic natural selection using a picture-storybook intervention. Psychological Science, 25(4), 893-902. https://doi.org/10.1177\%2F0956797613516009

Kenyon, L., Schwarz, C., \& Hug, B. (2008). The benefits of scientific modeling: Constructing, using, evaluating, and revising scientific models helps students advance their scientific ideas, learn to think critically, and understand the nature of science. Science and Children, 46(2), 40-44.

Kirschner, P. A., Sweller, J., \& Clark, R. E. (2006). Why minimal guidance during instruction does not work: An analysis of the failure of constructivist, discovery, problem-based, experiential, and inquiry-based teaching. Educational Psychologist, 41(2), 75-86. 
Are preschoolers expected to learn difficult science...

http://dx.doi.org/10.1207/s15326985ep4102 1

Kloos, H., \& Sloutsky, V. (2008). What's behind different kinds of kinds: Effects of statistical density on learning and representation of categories. Journal of Experimental Psychology: General, 137(1), 52-72. http://dx.doi.org/10.1037/0096-3445.137.1.52

Kloos, H., Baker, H., \& Waltzer, T. (2019). A mind with a mind of its own: How complexity theory can inform early science pedagogy. Educational Psychology Review, 31(3), 735-752. https://doi.org/10.1007/s10648-019-09472-6

Kloos, H., Baker, H., Luken, E., Brown, R., Pfeiffer, D. \& Carr, V. (2012). Preschoolers learning science: Myth or reality? In H. Kloos, B. J. Morris \& J. L. Amaral (Eds.), Current topics in children's learning and cognition (pp. 45-70). Tech - Open Access Publisher. http://dx.doi.org/10.5772/54119

Kloos, H., Waltzer, T., Maltbie, C., Brown, R. D., \& Carr, V. (2018). Inconsistencies in early science education: Can nature help streamline state standards? Ecopsychology, 10(4), 243-258. http://doi.org/10.1089/eco.2018.0042

Krippendorff, K. (1989). Content analysis. In E. Barnouw, G. Gerbner, W. Schramm, T. L. Worth, \& L. Gross (Eds.), International encyclopedia of communication (Vol. 1, pp. 403-407). Oxford University Press. Retrieved from http://repository.upenn.edu/asc papers/226

Larimore, R. A. (2020). Preschool science education: A vision for the future. Early Childhood Education Journal, 48(6), 703-714. https://doi.org/10.1007/s10643-020-01033-9

Larson, A. L., \& Rahn, N. L. (2015). Vocabulary instruction on Sesame Street: A content analysis of the Word on the Street initiative. Language, Speech, and Hearing Services in Schools, 46(3), 207-221. https://doi-org.proxy.libraries.uc.edu/10.1044/2015 LSHSS-14$\underline{0079}$

Metz, K. E. (1995). Reassessment of developmental constraints on children's science instruction. Review of Educational Research, 65(2), 93-127. https://doi.org/10.3102/00346543065002093

National Center for Educational Statistics (NCES). (2021). The condition of education: Preschool and kindergarten enrollment (Annual Report). Institute of Educational Sciences (IES). https://nces.ed.gov/programs/coe/indicator_cfa.asp

Novak, J. D. (2010). Learning, creating, and using knowledge: Concept maps as facilitative tools in schools and corporations (2nd ed.). Lawrence Erlbaum Associates.

Oppermann, E., Hummel, T., \& Anders, Y. (2021). Preschool teachers' science practices: Associations with teachers' qualifications and their self-efficacy beliefs in science. Early Child Development and Care, 191(5), 800-814. http://dx.doi.org/10.1080/03004430.2019.1647191

Park, M. H., Dimitrov, D. M., Patterson, L. G., \& Park, D. Y. (2017). Early childhood teachers' beliefs about readiness for teaching science, technology, engineering, and mathematics. Journal of Early Childhood Research, 15(3), 275-291. http://dx.doi.org/10.1177/1476718X15614040

Piaget, J., \& Inhelder, B. (1969). The psychology of the child. Basic Books.

Piasta, S. B., Pelatti, C. Y., \& Miller, H. L. (2014). Mathematics and science learning opportunities in preschool classrooms. Early Education and Development, 25(4), 445-468. http://dx.doi.org/10.1080/10409289.2013.817753

Rosch, E. (1978). Principles of categorization. In E. Rosch \& B. B. Lloyd (Eds.), Cognition and categorization (pp. 27-48). Lawrence Erlbaum Associates. http://dx.doi.org/10.1016/B978-1-4832-1446-7.50028-5

Saçkes, M., Trundle, K. C., \& Bell, R. L. (2013). Science learning experiences in kindergarten and children's growth in science performance in elementary grades. Education and Science, 38(167), 112-125.

Saçkes, M., Trundle, K. C., \& Flevares, L. M. (2009). Using children's literature to teach standard-based science concepts in early years. Early Childhood Education Journal, 36(5), 415-422. http://dx.doi.org/10.1002/tea.20395

Saçkes, M., Trundle, K. C., Bell, R. L., \& O'Connell, A. A. (2010). The influence of early science experience in kindergarten on children's immediate and later science achievement: Evidence from the early childhood longitudinal study. Journal of Research in Science Teaching, 48(2), 217-235. https://doi.org/10.1002/tea.20395

Saidi, T., \& Sigauke, E. (2017). The use of museum based science centres to expose primary school students in developing countries to abstract and complex concepts of nanoscience and nanotechnology. Journal of Science Educational Technology, 26(5), 470-480. http://dx.doi.org/10.1007/s10956-017-9692-2

Sawyer, K. (Ed.). (2006). The Cambridge handbook of learning science. Cambridge University Press. http://dx.doi.org/10.1017/CBO9780511816833

Seefeldt, C., Galper, A., \& Jones, I. (2007). Active experiences for active children: Science. Pearson/Merill Prentice Hall.

Shtulman, A., Neal, C., \& Lindquist, G. (2016). Children's ability to learn evolutionary explanations for biological adaptation. Early Education and Development, 27(8), 1222-1236. http://dx.doi.org/10.1080/10409289.2016.1154418

Sobel, D. M., \& Legare, C. H. (2014). Causal learning in children. WIREs Cognitive Science, 5(4), $413-427$. 


\section{Ana OCASIO et al.}

https://doi.org/10.1002/wcs.1291

Sodian, B., Zaitchik, D., \& Carey, S. (1991). Young children's differentiation of hypothetical beliefs from evidence. Child Development, 62(4), 753-766. http://dx.doi.org/10.2307/1131175

Trundle, K. C., \& Smith, M. M. (2017). A hearts-on, hands-on, minds-on model for preschool science learning. Young Children, 72(1), 80-86. https://www.jstor.org/stable/10.2307/90001494

Tu, T. (2006). Preschool science environment: What is available in a preschool classroom? Early Childhood Education Journal, 33(4), 245251. https://doi.org/10.1007/s10643-005-0049-8

United States Bureau of Labor Statistics (2021, October 22). Preschool Teachers. BLS.gov. https://www.bls.gov/ooh/education-trainingand-library/preschool-teachers.htm

Vosniadou, S. (Ed.). (2009). International handbook of research on conceptual change. Routledge. http://dx.doi.org/10.4324/9780203874813

Wiser, M., \& Smith, C. L. (2008). Learning and teaching about matter in grades K-8: When should the atomic-molecular theory be introduced. In S. Vosniadou (Ed.), International handbook of research on conceptual change (pp. 205-239). Routledge.

Worth, K. (1999). Science in early childhood classrooms: Content and process. STEM in Early Education and Development. https://ecrp.illinois.edu/beyond/seed/worth.html 
Are preschoolers expected to learn difficult science...

\section{Appendix A: Coding Schemes}

Appendix A.1 Explanation of Codes for Non-Science Items

\begin{tabular}{|c|c|c|}
\hline Codes & Words and Phrases & Example \\
\hline Engineering & $\begin{array}{l}\text { Broadly: finding solutions, fixing something broken, creating a } \\
\text { non-scientific model } \\
\text { Specifically: solves problems, builds a structure, use tools in } \\
\text { play, develop procedures, invent }\end{array}$ & $\begin{array}{l}\text { "Construct a device to protect from } \\
\text { the sun" } \\
\text { "Solve problems by designing or } \\
\text { using tools" }\end{array}$ \\
\hline Math & $\begin{array}{l}\text { Broadly: counting, using numbers, doing math without } \\
\text { connection to science } \\
\text { Specifically: use numbers, use quantities, uses mathematical } \\
\text { thinking, counts }\end{array}$ & $\begin{array}{l}\text { "Uses number to represent quantity" } \\
\text { "When counting, assigns number to } \\
\text { each item" }\end{array}$ \\
\hline Language Arts & $\begin{array}{l}\text { Broadly: reading, writing, or speaking with a focus on the } \\
\text { process of language proficiency rather than science } \\
\text { Specifically: makes signs, uses letter-like symbols, writes } \\
\text { messages, listens to stories, tells stories, repeats words }\end{array}$ & $\begin{array}{l}\text { "Talk about ways to be safe" } \\
\text { "Repeat new words" }\end{array}$ \\
\hline Personal Growth & $\begin{array}{l}\text { Broadly: following the rules, learning norms, showing respect, } \\
\text { developing traits } \\
\text { Specifically: showing respect, follows rules, asks for help, invites } \\
\text { peers, develops personal interest, shows surprise }\end{array}$ & $\begin{array}{l}\text { "Demonstrate respect" } \\
\text { "Follows directions" }\end{array}$ \\
\hline Caring for Others & $\begin{array}{l}\text { Broadly: referred to volunteering time, assisting, helping } \\
\text { Specifically: Take care of, participate in care, express concern, is } \\
\text { considerate }\end{array}$ & $\begin{array}{l}\text { "Care for plants and animals in the } \\
\text { classroom" } \\
\text { "Participate in activities that help to } \\
\text { care for the environment" }\end{array}$ \\
\hline
\end{tabular}


Appendix A.2 Explanation of Codes for Inquiry Terms (Study 1)

\begin{tabular}{lll}
\hline Codes & Words and Phrases & Examples \\
\hline Unspecified & & \\
& become familiar; determine; develop a sense; \\
develop an awareness; engage in activities; explore; & "Explores what a variety of living organisms \\
find out; inquiry; interact with; investigate; know; & environment)" \\
learn; look for answers; manipulate; pursue & "Investigates concepts of structures." \\
& $\begin{array}{l}\text { questions; reason; reflect; seek information; think } \\
\text { about; try things out; understand }\end{array}$ &
\end{tabular}

Low Degree of Abstraction (Levels 1, 2)

Level 1:

Observe-without-

Tools

Level 2:

Observe-with-Tools collect data; collect information; discover; examine; gather information; make observations; manipulate; notice; observe; sensory exploration; use senses

explore with tools; gather information with tools; investigate with tools; measure; use books
"Observes the characteristics and movement of the sun, moon, stars, and clouds"

"Makes simple observations of the characteristics, movement, and seasonal changes of the sun, moon, stars, and clouds."

"Use tools to explore the properties and characteristics of objects"

"Uses simple tools for exploration and investigation."

Medium Degree of Abstraction (Levels 3, 4, 5)

Level 3:

Communicate-

without-Tools

Level 4:

Communicate-with-

Tools

Level 5:

Ask-Questions answer questions; confirm (observations); count; define; demonstrate (awareness, knowledge); describe; discuss; display data; document observations; draw; evaluate; give examples; identify; indicate (awareness, knowledge); infer; interpret; know vocabulary; label; name; offer critique; present; recall; recognize; record (data, information); represent; retell; share (explanations, findings, ideas); show understanding; summarize observations; take pictures; talk; use evidence

create maps; graph; use charts; use models; use tally sheets

be curious; demonstrate interest; express wonder; generate questions; show curiosity; show interest "Begins to use scientific vocabulary"
"Observes and describes characteristics, basic
needs, and simple life cycles of living things."

"Collect, describe, and record information through discussions, drawings, maps, and charts."

"Record observations using simple visual tools."

"Exhibits curiosity about objects, living things, and other natural events in the environment." "Asks and responds to questions about relationships of objects, living things, and events in the natural environment."

High Degree of Abstraction (Level 6, 7, 8, 9)

Level 6:

Compare-Contrast analyze data; categorize; classify; differentiate; discriminate; distinguish; match something with something else; order; organize; sort

Level 7:

Predict anticipate; formulate hypothesis; make guesses; make predictions; predict changes
“Compares and categorizes solids and liquids based on their physical properties" "Compares baby and adult animals and recognizes similarities (e.g., matches adult stuffed animals with their baby in a play setting)"

"Make predictions about changes in materials or objects based on past experience."

"Describe and anticipate weather changes." 
Are preschoolers expected to learn difficult science...

Level 8:

Test-a-Prediction

Level 9:

Explain check predictions; experimentation (engage in, explore through); participate in experiments; test hypotheses; verify predictions

conclude (draw, formulate, make conclusions); explain; form explanations; generalize; generate explanations
"Test a variety of materials and configurations to design an end product."

"Adjusts their approach if results are different than expected and continues testing."

"Constructs theories to explain their investigations."

"Develops increasingly detailed explanations of their ideas and reasons" 
Appendix A.3 Explanation of Codes for Domains of Science (Study 2)

\begin{tabular}{lll}
\hline Codes & Words and Phrases & Examples \\
\hline Life Science & \\
& Broadly: biology, organism(s), life & $\begin{array}{l}\text { "Uses senses to observe and describe the } \\
\text { properties of familiar plants and animals" }\end{array}$ \\
Specifically: plants, animals, growth, senses, living objects, effect on & $\begin{array}{l}\text { "Ask and answer questions about changes } \\
\text { in the appearance, behavior, and habitats } \\
\text { living things (e.g., of the weather, habitats, environment, seasons) }\end{array}$ & $\begin{array}{l}\text { of living things." } \\
\end{array}$
\end{tabular}

Physical Science

Broadly: physics, chemistry.

Specifically: objects, motion, sound, light, vibrations, forces, magnetism, materials, matter, circumstances, physical models, physical structures, speed, fast/slow, heating/cooling, melting/freezing, light as energy, light variations, shadows, sinking, floating, temperature, things, states of matter

Earth/Space Science

Broadly: astronomy, meteorology, geology

Specifically: earth materials, objects in the sky, sun, moon, stars, water cycle, rock cycle, day/night (cycles), natural objects, natural resources, materials in the environment, changes in the environment, non-living things in the environment (e.g., rocks, minerals, water), seasons, weather, impact of weather on the environment
"Investigates and describes different types or speeds of motion"

"Use objects to effect motion (e.g. build a ramp with blocks so the car goes faster)"

\section{Other Science}

Broadly: technology, social science, methodology, complex systems, environmentalism.

Specifically: effects on daily life (e.g., of the weather), effect of own actions, family, culture, digital media/devices, tools, scientific principles/process, caring for the planet, conservation, recycle/reuse, climate change, environmental concerns, pollution, human impact on earth/weather/seasons, uses of water, complex concepts, guidelines, day/night activities, human use of materials/resources/etc.
"Describe how the Earth's surface is made up of different materials"

"Observe, describe, and discuss the characteristics of the sun, moon, stars, and sky"

\section{Multiple Sciences}

Combinations (2 or more) of the above categories (Life, Physical, Earth/Space, or Other)

\section{Unclear domain of science}

"Explains why a simple machine is appropriate for a particular task" "Explore and use simple tools and machines."
World, data, information, environment, nature, events
"Explore concepts and information about the physical, earth, and life sciences" "Discriminate between living organisms and non-living objects"
"Ask questions to find out more about the natural world."

"Displays and interprets data." 
Appendix A.4 Explanation of Codes for Facts (Study 2)

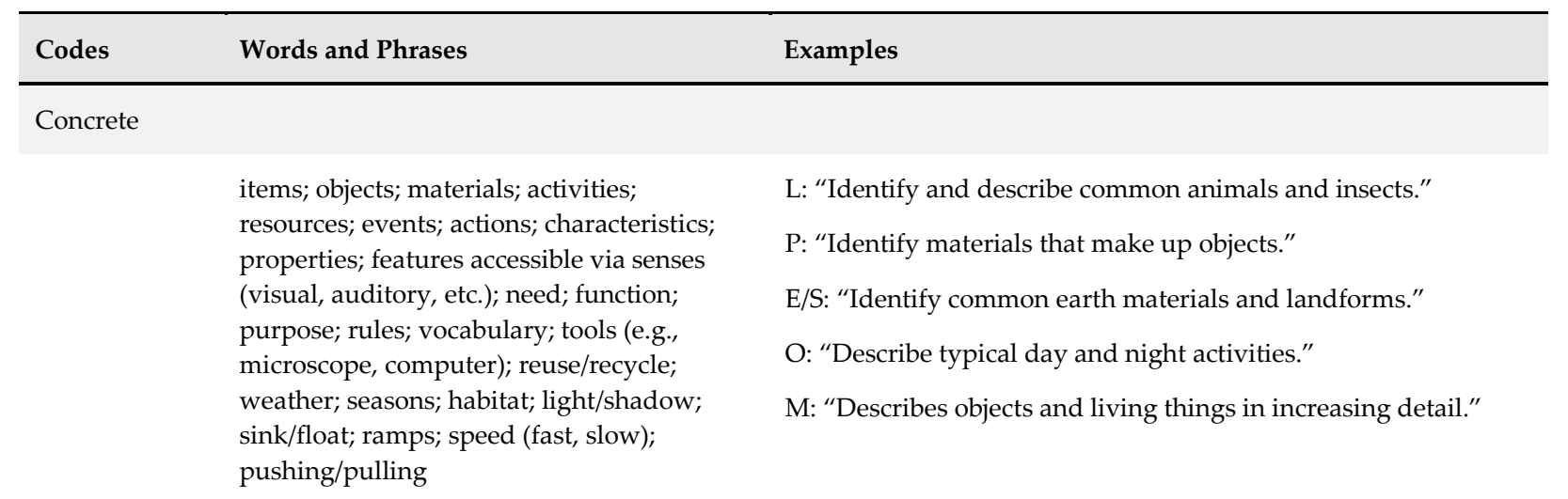

Abstract

Relations

affect; impact; interact; influence; control; cause/effect; why $\mathrm{X}$ happens; result of; respond to; generate; depend on; provide for; take care of; protect; preserve; system; family; heredity; offspring; density

Patterns

patterns; changes; cycles (e.g., rock, water); stages; sequence; routine; growth; moving/motion; stability; transformation (e.g., solids to liquids); melting/freezing; heating/cooling; dissolving; polluting

Groups

Forces groups; categories; kinds of; types of; similarities/differences among groups (e.g., mammals; species; age group; living/nonliving); $X$ as $Y$ (e.g., "wetland as an ecosystem"); $X$ vs. $Y$; $X$ to $Y$ (young to old); $X$ from $Y$; models.

force; inertia; friction; buoyancy; magnetism; electricity; gravity; falling without support; vibrations making a sound; energy; light (when a source of energy); heat (when a source of energy)
L: "Asks questions about the relationship between two things (e.g., Why do you think some animals sleep in the day?)."

P: "Investigate different sounds made by different objects and different materials."

E/S: “Demonstrates, through observation and investigation, an understanding that human action impacts the earth"

O: "Identify how weather affects daily life."

M: "Asks and responds to questions about relationships of objects, living things, and events in the natural environment."

L: "Demonstrates an understanding that living things change over time in size and other capacities as they grow".

$\mathrm{P:}$ " Explore and describe in greater detail changes in objects and materials."

E/S: "Uses senses and tools (including technology) to observe, describe, discuss and generate questions about changes in weather over time"

O: “Understands how actions people take may change the environment"

M: "Show an awareness of changes that occur in oneself and the environment."

L: "Compares baby and adult animals and recognizes similarities."

P: "Explore different kinds of matter and describe by observing properties."

E/S: “Identify various types of moving water"

O: "Describe the types of clothing needed for different seasons."

M: “Begins to describe the similarities, differences and relationships between objects, living things and natural events."

P: "Explore the effect of force on objects in and outside the early childhood environment."

P: "Describes and compares the effects of common forces on objects and the impact of gravity, magnetism and mechanical 


\section{Ana OCASIO et al.}

forces."

General Science

general statements about a domain of science; scientific principle; scientific process
L: "Ask questions and conduct investigations to understand life science."

E/S: "The child investigates and observes the basic concepts of the Earth"

O: "With prompting and support, use scientific vocabulary words to describe steps in the scientific process"

M: "Pose questions about the physical and natural environment."

Note. The acronyms pertain to the various domains of science (L: life science, P: physical science, E/S: earth/space science, O: other science, M: multiple sciences). 
Are preschoolers expected to learn difficult science...

\section{Appendix B: Number of Items and Terms per State}

Appendix B.1 Number of Inquiry Items and Terms (Study 1)

\begin{tabular}{|c|c|c|c|c|c|c|c|c|}
\hline \multirow[b]{2}{*}{ State (Publication Year) } & \multicolumn{5}{|c|}{ Non-Science Items } & \multirow[b]{2}{*}{ Science Items } & \multicolumn{2}{|c|}{ Inquiry Terms } \\
\hline & $\mathrm{E}$ & M & LA & PG & $\mathrm{CfO}$ & & Unspecified Items & Specified Terms \\
\hline Alabama (2012) & 1 & & & 1 & & 17 & 2 & 26 \\
\hline Alaska (2007) & & & & & 1 & 14 & 2 & 17 \\
\hline Arizona (2018) & & & & 1 & & 14 & 1 & 14 \\
\hline Arkansas (2016) & 1 & & & 2 & & 24 & 4 & 31 \\
\hline California (2012) & & & & & & 25 & 7 & 32 \\
\hline Colorado (2011) & & & & & & 11 & 1 & 22 \\
\hline Connecticut (2014) & & & & & & 15 & 3 & 15 \\
\hline Delaware (2010) & & & & 1 & & 20 & 4 & 27 \\
\hline Florida (2019) & 2 & & & 1 & & 26 & 5 & 30 \\
\hline Georgia (2019) & 1 & & & & & 17 & 7 & 21 \\
\hline Hawaii (2014) & & & & & & 11 & 3 & 16 \\
\hline Idaho (2014) & 1 & 5 & 12 & 15 & & 31 & 6 & 41 \\
\hline Illinois (2013) & & 1 & & 2 & & 18 & 5 & 27 \\
\hline Indiana (2014) & & 2 & & & & 20 & 1 & 23 \\
\hline Iowa (2017) & & & & & & 6 & 4 & 3 \\
\hline Kansas (2014) & & & & & & 13 & 3 & 15 \\
\hline Kentucky (2010) & & & & & & 14 & 0 & 18 \\
\hline Louisiana (2013) & & & & 1 & 1 & 21 & 3 & 30 \\
\hline Maine (2015) & 6 & & 1 & & & 19 & 3 & 31 \\
\hline Maryland (2010) & 1 & & 1 & & & 13 & 2 & 23 \\
\hline Massachusetts (2010) & & & & & & 30 & 7 & 35 \\
\hline Michigan (2013) & & & & & & 17 & 2 & 25 \\
\hline Minnesota (2014) & 3 & & & 2 & & 15 & 3 & 14 \\
\hline Mississippi (2018) & 3 & & & & & 28 & 8 & 32 \\
\hline Missouri (2013) & 3 & & & & & 9 & 6 & 3 \\
\hline Montana (2014) & 3 & & & 3 & & 37 & 10 & 39 \\
\hline Nebraska (2018) & & & & & & 13 & 3 & 12 \\
\hline Nevada (2010) & & & 1 & & & 46 & 28 & 25 \\
\hline New Hampshire (2011) & & & & & & 4 & 1 & 3 \\
\hline
\end{tabular}




\section{Ana OCASIO et al.}

New Jersey (2014)

New Mexico (2017)

North Carolina (2013)

2

Ohio (2019)

Oklahoma (2016)

1

Oregon (2016)

Rhode Island (2013)

South Carolina (2017)

Tennessee (2019)

Texas (2015)

Utah (2013)

Vermont (2015)

Virginia (2013)

Washington (2012)

West Virginia (2019)

1

2

1

Wisconsin (2013)

2

1

Wyoming (2009)

15

14

\section{Total}

40

19

34

19

Note. Items differed in whether they pertain to science (science items) or not (non-science items). Non-science items could be about engineering (E), math (M), language arts (LA), personal growth (PG), or caring for others (CfO). Appendix A.1 provides detailed information about the non-science items were defined. For science items, the abstraction level of their inquiry terms was coded. Inquiry terms could be unspecified (i.e., too vague to fit a single abstraction code), or they could be specified (i.e., precise enough for an abstract code). Items with only unspecified inquiry terms were referred to as unspecified items. 
Are preschoolers expected to learn difficult science...

Appendix B.2 Number of Fact Items and Terms (Study 2)

\begin{tabular}{|c|c|c|c|c|c|c|c|c|c|c|c|}
\hline \multirow[b]{2}{*}{ State } & \multirow{2}{*}{$\begin{array}{c}\text { Items } \\
\text { without } \\
\text { Domain }\end{array}$} & \multicolumn{5}{|c|}{ Items with Domains } & \multicolumn{5}{|c|}{ Fact Terms } \\
\hline & & $\mathrm{L}$ & $\mathrm{P}$ & $\mathrm{E} / \mathrm{S}$ & M & $\mathrm{O}$ & $\mathrm{Co}$ & $\mathrm{R}$ & $\mathrm{P}$ & G & $\mathrm{F}$ \\
\hline Alabama & 4 & 3 & 5 & 4 & & 1 & 9 & 1 & 3 & 2 & \\
\hline Alaska & 7 & 2 & 2 & 3 & & & 4 & 1 & 2 & & \\
\hline Arizona & 9 & & & & 5 & & 2 & 2 & 1 & & \\
\hline Arkansas & 9 & 5 & 3 & 1 & & 6 & 9 & 2 & 3 & 1 & \\
\hline California & 4 & 6 & 8 & 3 & 2 & 2 & 10 & 3 & 9 & 1 & \\
\hline Colorado & 3 & 3 & 4 & 1 & & & 2 & 2 & 4 & 1 & \\
\hline Connecticut & 6 & 3 & 4 & & 1 & 1 & 1 & 5 & 5 & 1 & \\
\hline Delaware & 7 & 4 & 2 & 3 & 2 & 2 & 5 & 3 & 2 & 3 & \\
\hline Florida & 7 & 6 & 5 & 4 & 2 & 2 & 8 & 4 & 7 & 1 & \\
\hline Georgia & 3 & 3 & 5 & 4 & 1 & 1 & 5 & 2 & 7 & 2 & \\
\hline Hawaii & & 2 & 5 & 2 & 1 & 1 & 3 & 2 & 4 & 3 & \\
\hline Idaho & 17 & & 7 & 2 & $2^{*}$ & 2 & 8 & 4 & 1 & & \\
\hline Illinois & 7 & 2 & 4 & 2 & 1 & 2 & 5 & 3 & 3 & & 2 \\
\hline Indiana & 4 & $2^{*}$ & 6 & 4 & 1 & 2 & 7 & 1 & 4 & 3 & 1 \\
\hline Iowa & 3 & & 1 & & 2 & & 1 & & 2 & 1 & \\
\hline Kansas & & 3 & 2 & 1 & 2 & 5 & 4 & 8 & 3 & & 1 \\
\hline Kentucky & 8 & & 6 & & & & 5 & 1 & & & \\
\hline Louisiana & 5 & 5 & 3 & 3 & 2 & $2^{*}$ & 4 & 2 & 8 & 2 & 1 \\
\hline Maine & 4 & 5 & 5 & 3 & & 2 & 8 & 4 & 3 & & 1 \\
\hline Maryland & 3 & 2 & 7 & 1 & & & 3 & 3 & 2 & 2 & 3 \\
\hline Massachusetts & 1 & 9 & 9 & 4 & 4 & 3 & 12 & 9 & 7 & 4 & \\
\hline Michigan & 4 & 4 & 2 & 4 & 3 & & 7 & 2 & 3 & 1 & \\
\hline Minnesota & 11 & & 1 & & & $2^{*}$ & 1 & 2 & & & \\
\hline Mississippi & 3 & 11 & 7 & 3 & 4 & & 15 & 2 & 8 & & 1 \\
\hline Missouri & & 3 & $2^{*}$ & 3 & & & 8 & & & & \\
\hline Montana & 5 & 7 & 11 & 12 & 2 & * & 22 & 1 & 6 & 1 & 1 \\
\hline Nebraska & 8 & 1 & 2 & & 2 & & 3 & 1 & & 1 & \\
\hline Nevada & 7 & 15 & 13 & 6 & 2 & $2^{*}$ & 24 & 7 & 6 & 2 & 3 \\
\hline New Hampshire & & 1 & 1 & 1 & & 1 & 2 & & 2 & & 1 \\
\hline
\end{tabular}




\begin{tabular}{|c|c|c|c|c|c|c|c|c|c|c|c|}
\hline \multicolumn{12}{|c|}{ Ana OCASIO et al. } \\
\hline New Jersey & 2 & 5 & 7 & 1 & 6 & & 7 & 5 & 5 & 3 & 1 \\
\hline New Mexico & 6 & & & 4 & & & & 1 & 2 & 1 & \\
\hline New York & & 4 & 7 & 3 & 3 & 1 & 9 & 5 & 2 & 2 & 1 \\
\hline North Carolina & 11 & 1 & 5 & 1 & & 1 & 5 & & 2 & 1 & \\
\hline North Dakota & 3 & & & & 1 & & 1 & & & & \\
\hline Ohio & 9 & 5 & 3 & 3 & * & & 6 & 2 & 3 & 1 & \\
\hline Oklahoma & 11 & 5 & 11 & $6^{*}$ & 1 & 3 & 21 & 1 & 3 & 1 & \\
\hline Oregon & 7 & 6 & 8 & 3 & 2 & 1 & 10 & 5 & 6 & 1 & \\
\hline Pennsylvania & & 12 & 7 & 9 & 4 & 12 & 24 & 6 & 10 & 5 & 3 \\
\hline Rhode Island & 5 & 6 & 5 & & 2 & 1 & 4 & 2 & 5 & 5 & \\
\hline South Carolina & 7 & 2 & 7 & 2 & 1 & & 8 & 1 & 4 & & \\
\hline South Dakota & 10 & 4 & 9 & 3 & 2 & 2 & 11 & 4 & 8 & & \\
\hline Tennessee & 4 & 3 & 4 & 2 & 2 & 2 & 8 & 2 & 4 & 1 & \\
\hline Texas & & 3 & 4 & 3 & & & 5 & 1 & 3 & & 1 \\
\hline Utah & 3 & 4 & 3 & 3 & 1 & & 8 & & 2 & 1 & \\
\hline Vermont & 2 & 6 & 8 & 5 & 1 & & 9 & 1 & 8 & 5 & \\
\hline Virginia & 5 & 4 & 10 & 5 & 2 & 8 & 19 & 4 & 5 & 1 & 2 \\
\hline Washington & 5 & 1 & 1 & 2 & & & 3 & & 1 & & \\
\hline West Virginia & 6 & 1 & 1 & 1 & 1 & 2 & 3 & 2 & 1 & & \\
\hline Wisconsin & 12 & & 1 & & 2 & & 2 & & & 1 & \\
\hline Wyoming & 5 & 1 & 3 & & & & 2 & 1 & 1 & & \\
\hline Total & 262 & 181 & 237 & 129 & 74 & 76 & 362 & 120 & 180 & 61 & 23 \\
\hline
\end{tabular}

Note. Items differed in whether they could be attributed to a domain of science (items with domains) or not (items without domains). Domains refer to life science $(\mathrm{L})$, physical science $(\mathrm{P})$, earth/space science $(\mathrm{E} / \mathrm{S})$, other science $(\mathrm{O})$, and multiple sciences (M). Appendix A.3 provides detailed information about how the domains of science were defined. The fact terms differ in whether they were concrete only $(\mathrm{Co})$, a relation $(\mathrm{R})$, a pattern $(\mathrm{P})$, a group $(\mathrm{G})$, or a force $(\mathrm{F})$.

${ }^{*}$ reflects the presence of any additional items not included in the count that were too broad to receive a code for their abstraction level (e.g., "life science"). 